\title{
Charpy impact resistance of alkali treated curaua reinforced polyester composites
}

\author{
Ailton da Silva Ferreira ${ }^{\mathrm{I}}$, Felipe Perissé Duarte Lopes ${ }^{\mathrm{I}}$, Sergio Neves Monteiro ${ }^{\mathrm{I}}$, Kestur Gundappa \\ Satyanarayana ${ }^{\text {II }}$ \\ I State University of the Northern Rio de Janeiro, UENF, Advanced Materials Laboratory, LAMAV; Av. \\ Alberto Lamego, 2000, 28013-602, Campos dos Goytacazes, Brazil. \\ e-mail: ailtonsilvaferreira@yahoo.com.br ; felipeperisse@pop.com.br ; sergio.neves@ig.com.br \\ ${ }^{\text {II }}$ Acharya Research \& Development Center, Soladevanhalli, Bangalore, India. \\ e-mail: kgs_satya@yahoo.co.in
}

\begin{abstract}
Natural fibers obtained from cellulose-based plants are being used as reinforcement of polymer composite owing to both environmental and technical advantages. One important technical characteristic of most lignocellulosic fibers is the bend flexibility, which allows them to resist impact forces. As a consequence, there is an increasing application of these lignocellulosic fibers in automobile parts that, during a crash event, should absorb the impact energy without splitting into sharp pieces. The present work investigates the toughness behavior of polyester composites reinforced with up to $30 \%$ in volume of alkali treated continuous and aligned curaua fibers by means of Charpy impact tests. It was found that the incorporation of treated curaua fibers increased the composite absorbed impact energy but not as much as in composites reinforced with non-treated fibers. Macroscopic observation, and scanning electron microscopy analysis of fracture surface, revealed that the main mechanism for the increase in the Charpy notch toughness is the interfacial rupture between the curaua fiber and the polyester matrix.
\end{abstract}

Keywords: Curaua fiber, polyester composite, fiber alkali treatment, Charpy test, fracture analysis.

\section{INTRODUCTION}

The use of polymer composites reinforced with natural fiber obtained from cellulose-based plants such as flax, coir, sisal and curaua is increasing in the automobile industry with annual growth rates above $20 \%$ [1]. In addition to economical and environmental advantages, the higher impact resistance of natural fiber composites is a major motivation for uses in both interior and exterior components. The impact resistance is of considerable importance in the case of a crash accident in which parts like the head rest or the front panel should not break in a brittle manner deploying sharp pieces.

Among the natural lignocellulosic fibers, that extracted from the leave of the curaua (Ananas erectifolius) is one of the strongest and most flexible [2]]. Recent works [므므] on the impact resistance of polymer composites reinforced with continuous and aligned curaua fiber have shown a significant increase in toughness with the amount of incorporated fiber. In fact, the toughness measured by the absorbed impact energy in both Charpy and Izod test increases linearly up to volume fractions of $20-30 \%$ of curaua fibers reinforcing either polyester $[\underline{3}, \underline{6}]$ or epoxy $[\underline{4}, \underline{5}]$ matrices. Values of impact energy above $100 \mathrm{~J} / \mathrm{m}$ were obtained for continuous and aligned fiber composite $[\underline{3}, \underline{6}]$ as compared to only $54 \mathrm{~J} / \mathrm{m}$ for polypropylene composite reinforce with $50 \mathrm{wt} \%$ of short cut and randomly oriented curaua fibers [7].

In spite of the relatively good results obtained for composites reinforced with continuous and aligned fibers there is still a possibility to further improve the impact resistance by increasing the adhesion between the curaua fibers and the polymeric matrix. In principle this could be done by means of a surface treatment that could reduce the hydrophilic condition of the lignocellulosic fiber and then improve its interfacial bonding with the hydrophobic polymer matrix [8].

The effect of an alkali treatment using caustic soda $(\mathrm{NaOH})$, also known as mercerization, has been investigated in curaua fibers reinforced epoxy composites $[\underline{9}, \underline{10}]$. In these works no significant improvement on the strength on the composites was found for alkali treated as compared to non-treated curaua fibers. For volume fraction of fibers above $30 \%$, however, a slightly better reinforcement was observed. This motivates the present works in which the Charpy impact resistance of polyester composites reinforced with up to $30 \%$ in volume of alkali treated continuous and aligned curaua fibers was investigated. 


\section{EXPERIMENTAL PROCEDURE}

Curaua fiber in the form of a bundle, Figure 1(a), were supplied by the Brazilian firm Amazon Paper. The soft fibers were individually separated, Figure 1(b) for a statistical dimensional analysis. The measured distribution of 100 fibers revealed [3-6] a dispersion interval in length from 650 to $1000 \mathrm{~mm}$, with an average of $846 \mathrm{~mm}$. A dispersion in diameter from 0.03 to $0.15 \mathrm{~mm}$, with an average of $0.07 \mathrm{~mm}$ was also revealed.
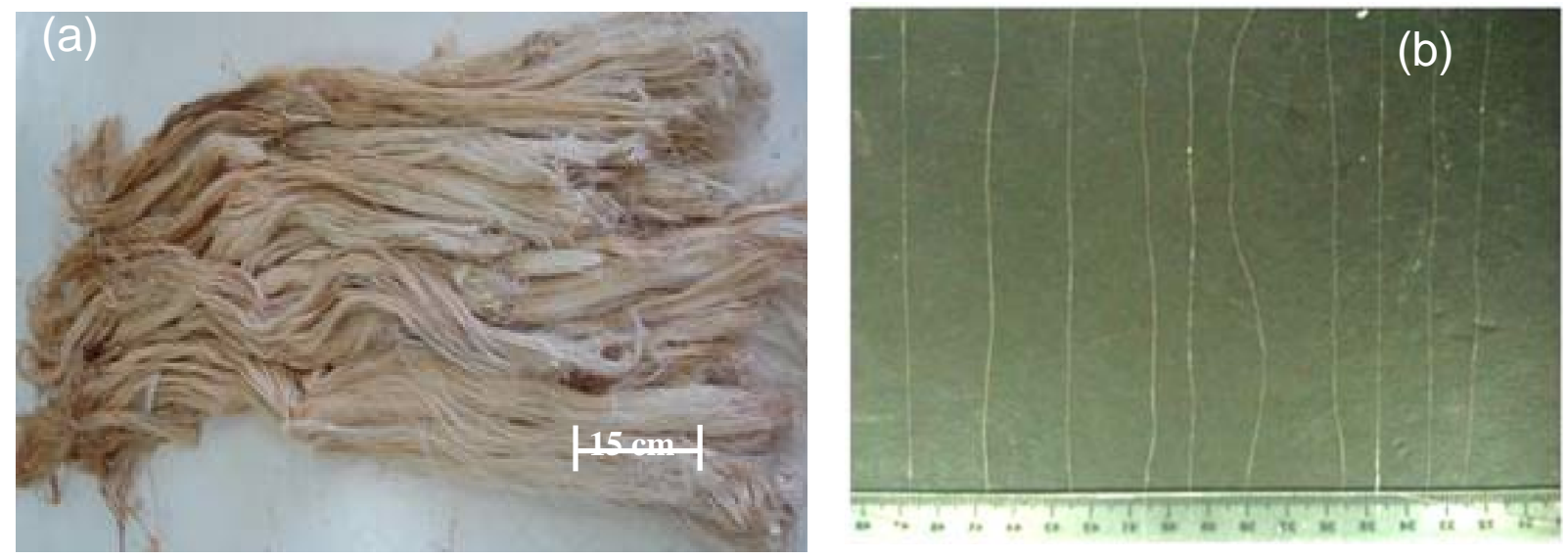

Figure 1: The bundle of curaua fibers obtained for this work (a) and separated fibers (b).

Two distinct lots of fibers separated from the bundle were submitted to both a strong alkali treatment by immersion during one hour in a $10 \% \mathrm{NaOH}$ solution and a weak treatment during one minute in a $0.1 \% \mathrm{NaOH}$ solution. These treatments were followed by a thorough water rinse and then drying in a stove at $60^{\circ} \mathrm{C}$ for 24 hours. Another lot of non-treated fibers was just clean in water and then dried for comparative analysis.

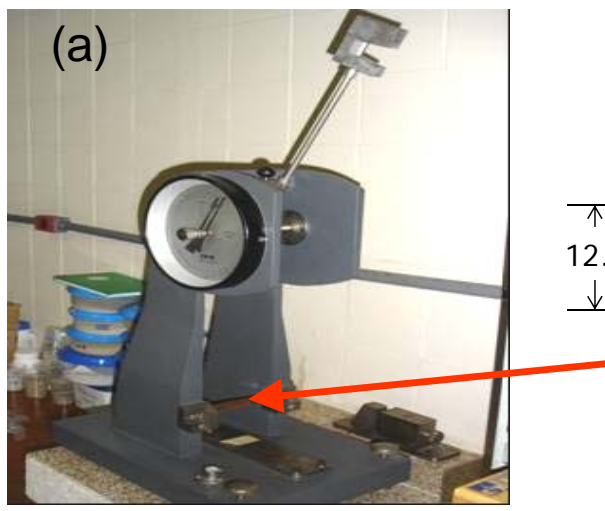

(b)
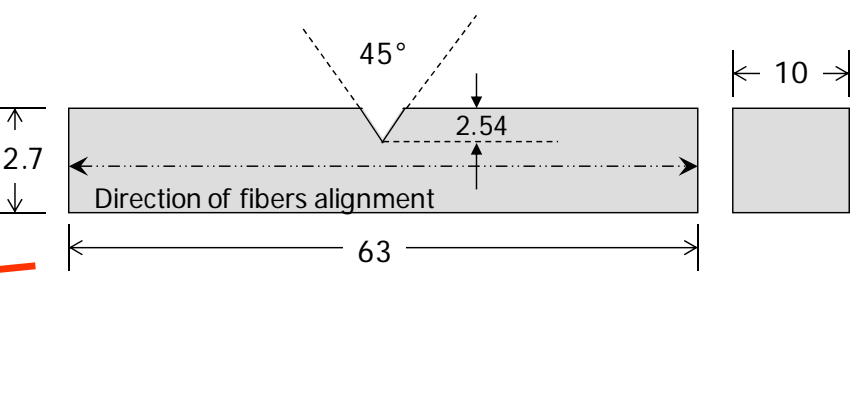

Figure 2: Charpy equipment and schematic standard Charpy specimen.

Composite fabrication was performed as followed. Continuous and aligned curaua fibers were layed down on a $152 \mathrm{x} 125 \mathrm{~mm}$ steel mold together with a still fluid commercial orthophtalic polyester resin added with $0.5 \%$ metyl-ethyl-ketone hardener. Plates of these composites with amounts of up to $30 \%$ in volume fraction of fibers were press-molded and allowed to cure at room temperature for 24 hours. Standard ASTM D 256 Charpy notched specimens, Figure 2, with 125 x 127 x $10 \mathrm{~mm}$ were cut from the plates with fibers aligned along the specimen length. For each plate corresponding to a given volume fraction, 10 specimens 
were machined with a $2.54 \mathrm{~mm}$ deep notch, angle of $45 \mathrm{o}$ and a tip radius of $0.25 \mathrm{~mm}$. These specimens were impact tested in an EMIC pendulum machine, Figure 2(a), equipped with Charpy hammers for different striking energy. A $2.7 \mathrm{~J}$ hammer was used for the pure polyester specimens as well as for specimens with 10 and $20 \%$ of curaua fiber. A $5.4 \mathrm{~J}$ hammer was used for specimens with $30 \%$ of curaua fibers.

The fracture surface of some representative specimens was analyzed by scanning electron microscopy (SEM) in a model SSX-550 Shimadzu equipment operating with secondary electron at an accelerating voltage of $15 \mathrm{kv}$.

\section{RESULTS AND DISCUSSION}

The variation of the Charpy impact energy with the volume fraction of curaua fibers is shown in Fig. 3 for the investigated polyester composites. In this figure an increase in the composite absorbed energy can be seen, for both alkali treated and non-treated curaua fibers, as a function of the volume fraction. Composites reinforced with non-treated curaua fibers display an almost linear increase in the absorbed impact energy. Within the error bars, this increase can be translated by the equation:

$$
\mathrm{E}(\mathrm{J} / \mathrm{m})=4.3 \mathrm{~V}(\%)+4.7
$$

Composites reinforced with alkali treated curaua fibers also show a linear increase of the absorbed impact energy. For the weak treated fiber composites this increase is not as effective as that for the strong treated fiber composites. However, within the error bars, corresponding to the standard deviation, a linear fitting could be adjusted in both cases by the following equation:

$$
\mathrm{E}(\mathrm{J} / \mathrm{m})=0.9 \mathrm{~V}(\%)+4.7
$$

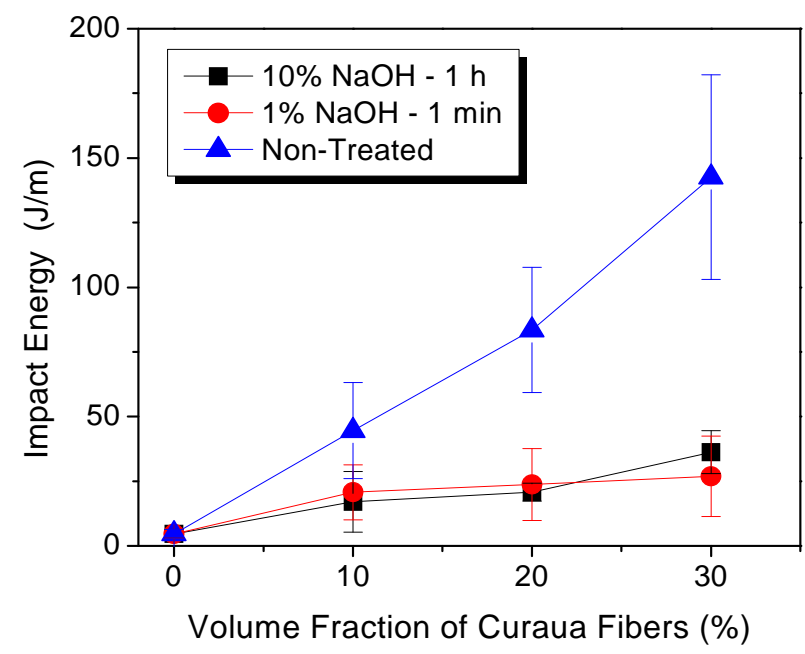

Figure 3: Charpy impact energy as a function of the volume fraction of curaua fibers reinforced polyester composites.

The inclination of the straight line associated with Eq. 2 is markedly lower than that of Eq. 1. This implies that the impact resistance of alkali treated is not as effective as that of non-treated curaua fiber reinforced epoxy composites. The level of maximum impact energy, of the order of $35 \mathrm{~J} / \mathrm{m}$, reached for the $30 \%$ of alkali treated curaua fibers in Figure 3 is significantly lower than the corresponding for non-treated fibers of the order of $150 \mathrm{~J} / \mathrm{m}$.

Although the introduction of alkali treated curaua fiber increases the toughness of polyester composites, Figure 3, the values are well below those obtained not only for non-treated curaua fibers, also shown in Figure 3, but also for other non-treated lignocellulosic fiber composites. Table 1 compares values of Charpy absorbed impact energy of polymeric composites reinforced with continuous and aligned lignocellulosic fibers. In this table, it is worth mentioning that among the selected data, the present results on alkali treated curaua fibers reinforcing polyester composites are the ones with the lowest impact energy. 
The increase in the notch toughness of polymer composites reinforced with continuous and aligned lignocellulosic fibers has been reported not only for curaua fibers [ $\underline{3}-\underline{6}]$ but also for other natural fibers [1118]. This toughness increase was mainly attributed to the low interface shear stress between a hydrophilic lignocellulosic fiber and a hydrophobic polymeric matrix [19]. In the case of a pure polymeric Charpy specimen, without fiber reinforcement, the crack nucleated by the striking hammer at the notch propagates transversally through the brittle polymer until complete rupture. The incorporation of continuous and aligned lignocellulosic fibers, such as curaua, offers an obstacle to the propagation of an initial crack nucleated at the specimen notch, shown schematically in Figure 2(b). This obstacle causes others cracks to be nucleated at the weak fiber/matrix interface. These cracks then propagate longitudinally through the interface following the specimen length direction.

As compared to the transversal rupture of a pure polymeric specimen, $0 \%$ fiber, the longitudinal rupture through the weak lignocellulosic fiber interface results in a larger fracture area. This mechanism is, consequently, associated with a higher absorbed impact energy resulting in a corresponding higher notch toughness of the composite.

Table 1: Impact toughness of polymeric composites reinforced with continuous and aligned lignocellulosic fibers.

\begin{tabular}{c|c|c}
\hline $\begin{array}{c}\text { Composites with } 30 \% \text { in } \\
\text { volume of fibers }\end{array}$ & $\begin{array}{c}\text { Charpy Impact Energy } \\
\mathbf{( J / m )}\end{array}$ & Reference \\
\hline ramie/epoxy & 211.7 & {$[\underline{17}]$} \\
\hline ramie/polyester & 1004.8 & {$[\underline{15}]$} \\
\hline coir/polyester & 241.2 & {$[\underline{16}]$} \\
\hline coir/epoxy & 174.7 & {$[\underline{16}]$} \\
\hline curaua/polyester & 169.7 & {$[\underline{3}]$} \\
\hline curaua/epoxy & 103.2 & This work \\
\hline $\begin{array}{c}\text { curaua/polyester } \\
(10 \% \mathrm{NaOH}-1 \text { hour })\end{array}$ & 38 & This work \\
\hline curaua/polyester & 27 & \\
\hline$(0.1 \% \mathrm{NaOH}-1$ min $)$ & & \\
\hline
\end{tabular}

Another mechanism that may contribute to the increase in composite toughness is the difficult to break a strong and flexible lignocellulosic fiber. It was found that impact specimens with relatively large amounts of continuous and aligned lignocellulosic fibers, fail to split apart in separated pieces. Even if the brittle polymer matrix suffers complete rupture, the more flexible and stronger fiber resists the total collapse of the composite specimen.

The visual macrostructure aspects of representative, after test, specimens for the different volume fraction of strong alkali treated $(10 \% \mathrm{NaOH}-1$ hour) curaua fibers are shown in Figure 4 . In this figure, it should be noticed that specimens with 20 and $30 \%$ of fibers are still partially connected. In other words, these specimens did not split apart in two pieces as the 0 and $10 \%$ fiber specimens.

In fact, the pure polyester ( $0 \%$ fiber) specimen suffered a total transversal rupture owing to its brittle behavior. By contrast, for the 10\% fiber specimen, Figure 4, the initial crack also propagates transversally. However, the few existing curaua fibers block the initial crack and cause a partial longitudinal propagation of final cracks up to total rupture. A higher amount of curaua fibers, 20 and $30 \%$ in Figure 4, results in a predominant longitudinal crack propagation, through the weak interface, by fiber/matrix decohesion. In this case, many curaua fibers released from the matrix, do not break. These fibers bend after the impact enough to allow the specimen to be carried away by the hammer, without splitting apart. 


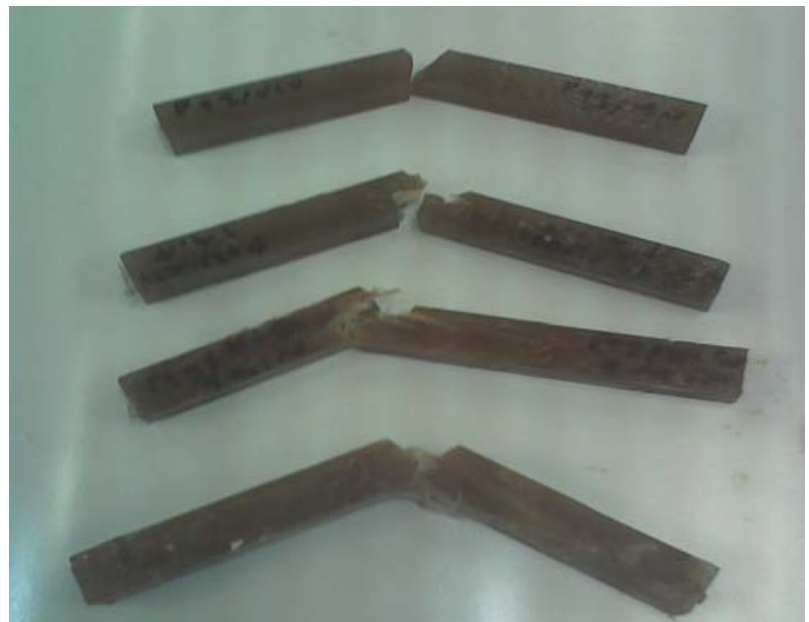

Figure 4: Microstructure aspect of strong alkali treated (10\% $\mathrm{NaOH}$ - 1hour) curaua fiber reinforced polyester specimens after Charpy impact tests.

The same macrostructural aspects were found for the weak alkali treated as well as for the nontreated curaua fiber composites. The difference in the impact resistance between the alkali treated and the non-treated fiber specimen is apparently not related to the above-mentioned fracture mechanism. It is suggested that a possible improvement in the curaua fiber interface with the polyester matrix, which may be caused by the alkali treatment, is surpassed by the deterioration of the fiber. This reduces the capacity of the fiber to resist the impact after its final release from the matrix.

SEM analysis of the Charpy impact fracture permitted to have a better comprehension of the mechanism responsible for the higher toughness of polyester composites reinforced with continuous and aligned curaua fiber. Figure 5 shows the aspect of the fracture surface of a pure polyester $(0 \%$ fiber $)$ specimen. With lower magnification, the uniform fracture surface, Figure 5(a), indicates that the rupture is caused by propagation of a single crack. With higher magnification, Figure 5(b), the typical crack propagation associated with "river pattern" marks are observed on the smooth brittle surface
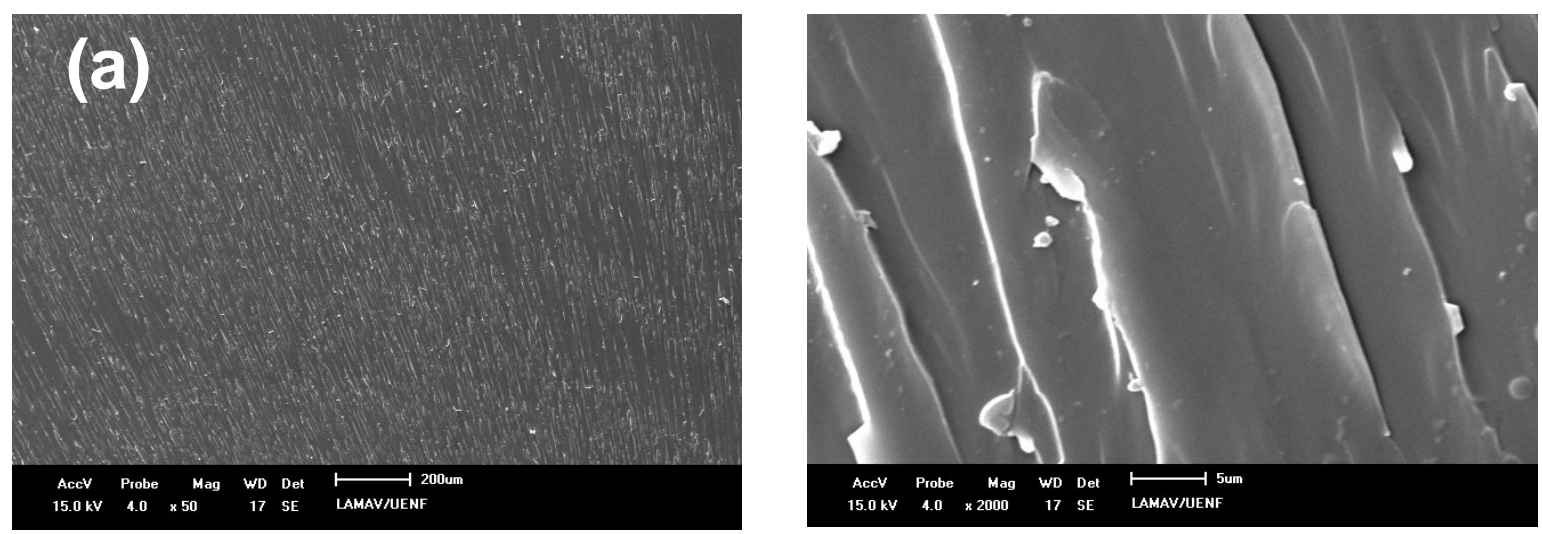

Figure 5: Charpy impact fracture surface of pure polyester specimen ( $0 \%$ fiber): (a) general view with lower magnification (50x) and (b) detail of the polyester fracture surface with higher magnification (2000x).

Figure 6 presents details of the impact fracture surface of a polyester composite specimen with $30 \%$ of strong alkali treated curaua fiber. These fractographs show evidence of decohesion between the fibers and the polyester matrix, Figure 6(a), where cracks preferentially propagate. Some of the fibers were pulled out from the matrix and others were broken during the impact. In Figure 6(b) the main transversal crack propagating through the brittle polyester matrix (left side) reaches a fiber (right side) causing decohesion and separation of fibrils. The many separated fibrils indicate that the alkali treatment has deteriorated the curaua fiber and consequently reduced its strength.

The greater fracture area, Figure 6, associated with the continuous and aligned curaua fibers acting as reinforcement for the composite, justify the higher absorbed impact energy, Figure 3, with increasing volume fraction. 

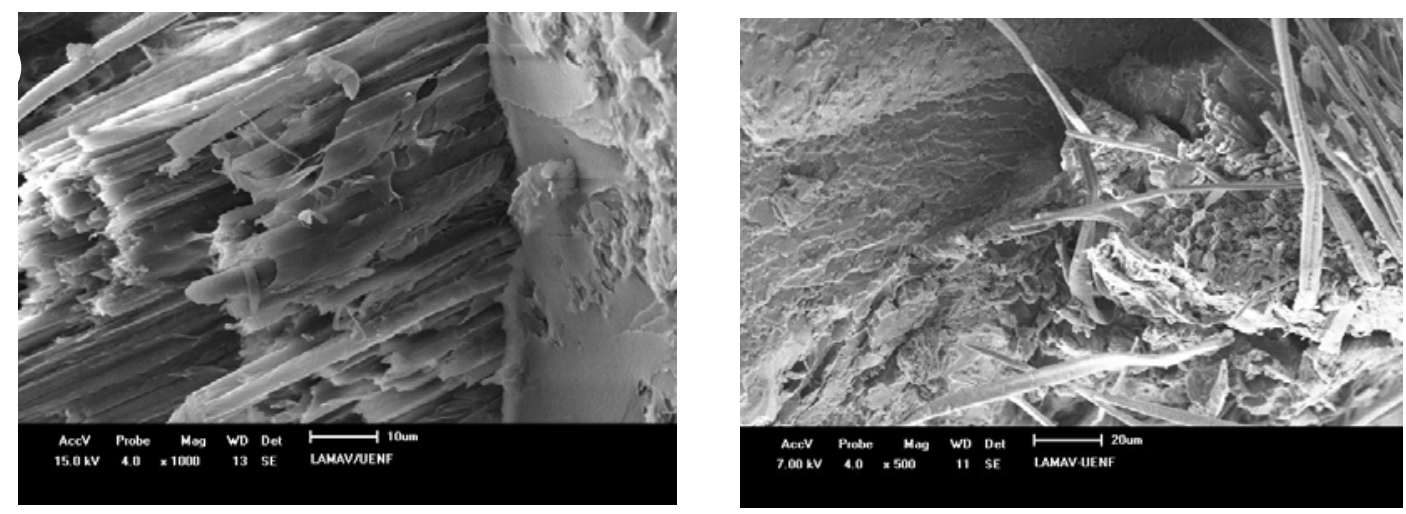

Figure 6: Charpy impact fracture surface of a polyester composite reinforced with $30 \%$ of strong alkali treated $(10 \% \mathrm{NaOH}-1$ hour) curaua fibers.

\section{CONCLUSIONS}

-Polyester composites reinforced with continuous and aligned curaua fibers display a linear increase in the notch toughness, measured by the Charpy impact energy, with the volume fraction. This linear increase is not as effective for alkali treated as compared to non-treated fibers.

-Both strong and weak alkali treatments, although improving the fiber/matrix adhesion, apparently deteriorate the curaua fibers causing a decrease in strength that reduces the fiber impact resistance after it suffers a final decohesion from the polyester matrix.

-In both cases, alkali treated and non-treated curaua fibers, above $10 \%$ of volume fraction, the composite specimen fails to split apart owing to the fiber flexibility that prevents total rupture. The specimen is bent during the impact enough to be carried away by the hammer.

-Macrostructure aspects and SEM fracture analysis revealed evidences of longitudinal crack propagation through the weak fiber/matrix interface. This causes larger ruptured areas that are associated with higher impact energy.

\section{ACKNOWLEDGEMENTS}

The authors thank the support to this investigation by the Brazilian agencies: CNPq, CAPES, FAPERJ and TECNORTE/FENORTE.

\section{REFERENCES}

[1] ZAH, R., HISCHIER, R., LEÃO, A.L., BRAUN, I., "Curaua fibers in the automobile industry - A sustainability assessment”, Journal of Cleaner Production, v. 15, pp. 1032-1040, 2007.

[2] SATYANARAYANA, K.G., GUIMARÃES, J.L., WYPYCH, F., "Studies on lignocellulosic fibers of Brazil. Part I: Source, production, morphology, properties and applications”, Composites: Part A, v. 38, pp. 1694-1709, 2007.

[3] MONTEIRO, S.N., LOPES, F.P.D., "Impact tests in polymeric composites reinforced with curauá fibers”, In: Proceedings of the 62nd International Congress of the Brazilian Association for Metallurgy and Materials. Vitoria, ES, Brazil, pp. 805-813, July, 2007.

[4] FERREIRA, A.S., MONTEIRO, S.N., LOPES, F.P.D., MENEZES, G.W., "Analysis of the impact strength of epoxy composites reinforced with aligned curauá fibers", In: Proceedings of the Brazilian Congress on Materials Science and Engineering, CBCIMAT, Porto de Galinhas, PE, Brazil, November 2008.

[5] FERREIRA, A.S., MONTEIRO, S.N., LOPES, F.P.D., AQUINO, R.C.M.P., "Analysis of the impact strength of epoxy composites reinforced with aligned curaua fibers”, In: Proceedings of the 63nd International Congress of the Brazilian Association for Metallurgy and Materials, Santos, SP, Brazil, pp. 805-813, July, 2008. 
[6] MONTEIRO, S.N., FERREIRA, A.S., LOPES, F.D.P., "Izod impact energy of polyester matrix composites reinforced with aligned curaua fibers", In: Proceedings of the Characterization of Minerals Metal \& Materials - TMS 2009, San Francisco, CA, USA, pp. 1-6, March, 2009.

[7] LEÃO, A.L., TAN, I.H., CARASCHI, J.C., "Curaua Fiber - A tropical natural fibre from Amazon Potential and Applications in Composites", In: Proceedings of the International Conference on Advanced Composites, Hurghada, Egypt, pp. 557-564, May, 1998.

[8] ROUT, J., MISRA, M., TRIPTHY, S.S., NAYAK, S.K., MOHANTY, A.K., "The influence of fibre treatment on the performance of coir-polyester composites", Composites Science and Technologies, v. 61, pp. $1303-1310,2001$.

[9] LOPES, F.P.D., SANTOS, L.F.L., MONTEIRO, S.N., "Effect of curaua fiber treatment on the mechanical properties of epoxy matrix composites", In: Proceedings of the 62nd International Congress of the Brazilian Association for Metallurgy and Materials, Vitoria, ES, Brazil, pp. 805813, July, 2007.

[10] FERREIRA, A.S., MONTEIRO, S.N., LOPES, F.P.D., AQUINO, R.C.M.P., "Effect of curauá fiber treatment on the mechanical properties of epoxy matriz composites", In: Proceedings of the 63nd International Congress of the Brazilian Association for Metallurgy and Materials, Belo Horizonte, MG, Brazil, July, 2009.

[11] BLEDZKI, A.K., GASSAN, J., “Composites reinforced with cellulose-based fibers”, Progress in Polymer Science, v. 4, pp. 221-274, 1999.

[12] CROCKER, J., “Natural materials innovative natural composites”, Materials Technology, v. 2-3, pp. 174-178, 2008.

[13] FU, S.Y., LAUKE, B., MÄDER, E., HU, X., YUE, C.Y., "Fracture resistance of short-glass-fiberreinforced and short-carbon-fiber-reinforced poly-propylene under Charpy impact load and dependence on processing”, Journal of Materials Processing Technology, v. 89/90, pp. 501-507, 1990.

[14] MONTEIRO, S.N., AQUINO, R.C.M.P., LOPES, F.P.D., CARVALHO, E.A., D’ALMEIDA, J.R.M., "Charpy impact notch toughness of piassava fibers reinforced polyester matrix composites", Revista Materia, v. 11, n. 3, pp. 204-210, 2006.

[15] MONTEIRO, S.N., MARGEM, F.M., SANTOS, L.F.L., "Impact tests in polyester matrix composites reinforced with ramie fibers" (in Portuguese), In: Proceedings of the 63rd International Congress of the Brazilian Association for Metallurgy and Materials, Santos, SP, Brazil, pp. 1-12, July, 2008.

[16] MONTEIRO, S.N., COSTA, L.L., SANTAFÉ, H.P.G., "Characterization of the Charpy impact resistance of coir fiber reinforced epoxy matrix composites", In: Proceedings of the 18th Brazilian Congress on Materials Science and Engineering - CBECIMAT, Porto de Galinhas, PE, Brazil, pp. 1-12, November, 2008.

[17] MONTEIRO, S.N., MARGEM, F.M., SANTOS JR., L.F.L., "Impact tests in epoxy matrix composites reinforced with ramie fibers", In: Proceedings of the 64rd International Congress of the Brazilian Association for Metallurgy and Materials, Belo Horizonte, Brazil, pp. 1-9, July, 2009.

[18] NASCIMENTO, D.C.O., MONTEIRO, S.N., MOTTA, L.C., "Characterization of the toughness of piassava fiber reinforced epoxy matrix composites by Izod impact tests", In: Proceedings of the Characterization of Minerals Metal \& Materials - TMS 2009, San Francisco, CA, USA, pp. 1-6, March, 2009.

[19] YUE, C.Y., LOOI, H.C., QUEK, M.Y., “Assessment of Fibre-Matrix Adhesion and Interfacial Properties Using the Pullout Test”, International Journal of Adhesion and Adhesives, v. 15, pp. 7380, 1995. 